\title{
Antibacterial Activities of New Schiff Bases and Intermediate Silyl Compounds Synthesized from 5-Substituted-1,10-phenanthroline- 2,9-dialdehyde
}

\author{
Zinia Jaman', Mohammad R. Karim ${ }^{1}$, Korsi Dumenyo², Aminul H. Mirza ${ }^{3}$ \\ ${ }^{1}$ Department of Chemistry, Tennessee State University, Nashville, USA \\ ${ }^{2}$ Department of Agriculture, Tennessee State University, Nashville, USA \\ ${ }^{3}$ Faculty of Science, Universiti Brunei Darussalam, Bandar Seri Begawan, Brunei \\ Email: mkarim@tnstate.edu
}

Received 4 October 2014; revised 12 November 2014; accepted 24 November 2014

Copyright (C) 2014 by authors and Scientific Research Publishing Inc.

This work is licensed under the Creative Commons Attribution International License (CC BY). http://creativecommons.org/licenses/by/4.0/

\section{(c) () Open Access}

\begin{abstract}
Schiff bases are known to possess anticancer, antibacterial, antifungal, antitubercular, anti-inflammatory, antimicrobial and antimalarial properties. In this paper antibacterial studies against variety of plants and human pathogenic bacteria with eight newly synthesized Schiff bases and several intermediate silyl compounds have been reported. The antibacterial activities of the synthesized compounds were primarily determined by paper disc diffusion method. The minimum inhibitory concentration (MIC) of each compound was also determined by tube dilution process. Seven different human pathogenic bacteria and eighteen different plant pathogenic bacteria were used for the antibacterial activity studies. While all synthesized compounds have shown significant antibacterial activity, one intermediate silyl compound has shown remarkably high antibacterial property. 5-substituted derivatives have shown relatively higher activity than non-substituted compounds. Polar substituent which increases hydrophilicity may have a positive impact on the antibacterial property.
\end{abstract}

\section{Keywords}

5-Nitro-1,10-phenanthroline Dialdehyde, 5-Bromo-1,10-phenanthroline Dialdehyde, Schiff Bases,

"Corresponding author.

How to cite this paper: Jaman, Z., Karim, M.R., Dumenyo, K. and Mirza, A.H. (2014) Antibacterial Activities of New Schiff Bases and Intermediate Silyl Compounds Synthesized from 5-Substituted-1,10-phenanthroline-2,9-dialdehyde. Advances in Microbiology, 4, 1140-1153. http://dx.doi.org/10.4236/aim.2014.415124 


\section{S-Alkyl/Aryldithiocarbazates, Thiosemicarbazide}

\section{Introduction}

Schiff base, named after Hugo Schiff, is another name of iminie functional groups or azomethine groups $(-\mathrm{C}=\mathrm{N})$ that are classically formed by condensation of a primary amine with an aldehyde or ketone [1]. Since various Schiff bases and their complexes have been formed and exhibited promising activity against bacteria and other microorganism, biochemists are interested to study Schiff bases for their medical importance and use in design of medicinal compounds [2] [3]. Many Schiff bases have antimicrobial and antifungal activities [4]. Additionally, aryl groups or heterocyclic residues containing Schiff bases possess excellent biological activities [5] [6].

Phenanthroline and its derivatives have significantly antibacterial, antifungal and anticancer activity [7]. Phenanthroline metal complex interacts with DNA by cleavage of the DNA strand involving interaction of the metal center with a phosphate group and cleavage of the phosphate ester bond [8] [9]. Also, some phenanthroline Schiff bases and their complexes are found to be photocleavers of pUC19 DNA in visible light and cytotoxic in HeLa (human cervical cancer) and MCF-7 (human breast cancer) cells in visible light [10]. Phenanthroline complexes exhibited high cytotoxicity in cancer cell lines, even sometimes higher activity than cis-platin and substitution at 5- or 5,6-position increases cytotoxicity such as the S, S isomer of complex is 100-fold more cytotoxic than of cis-platin in L2110 murine leukemia cell lines [11].

Schiff bases of thiosemicarbazone are very important due to their antimicrobial action [12]. Also, Schiff bases and their metal complexes having amino thiol group $\left(\mathrm{HN}_{2}-\mathrm{NH}-\mathrm{CS}-\mathrm{R}\right)$ show various biological activities. Thiosemicarbazone containing compounds can be used as drug against tuberculosis, leprosy [13] and tumor [14].

The biological study of Schiff bases containing 5-substituted-1,10-phenanthroline-2,9-dicarboxaldehyde with amines containing thione $(\mathrm{C}=\mathrm{S})$ groups has not been studied precisely. We, therefore, report here the antibacterial study of eight new Schiff bases containing 5-subntituted-1,10-phenanthroline moiety with different thiosemicarbazones. The intermediate silyl and aldehyde compounds are also studied against these bacteria.

\section{Materials and Methods}

\section{Preparation of test microorganism}

The sterilized (autoclaved for $30 \mathrm{~min}$ ) medium was poured into sterilized petri dish (500 $\mathrm{ml}$ for 20 petri dishes) and solidified $(1.5 \%, \mathrm{w} / \mathrm{v}$ agar) at room temperature for $30 \mathrm{~min} .18$ different types of plant pathogenic and 7 human pathogenic bacterial strains were used in this study of both gram positive and gram negative bacteria. A small amount of bacteria was collected from bacteria seed and streaked it onto an appropriate media plate for the bacteria. The plate was placed in a incubator for $24 \mathrm{~h}$ at $28^{\circ} \mathrm{C}$ for plant pathogenic bacteria and at $37^{\circ} \mathrm{C}$ for human pathogenic bacteria.

\subsection{Preparation of Reagents}

Fifteen compounds including eight new Schiff bases, four intermediates and one starting molecule were used for antibacterial screening test by using disk diffusion method (Table 1). The eight new Schiff bases were synthesized and characterized by using different spectroscopic methods including IR, ${ }^{1} \mathrm{H} N \mathrm{NMR},{ }^{13} \mathrm{C} \mathrm{NMR}$ and Mass spectroscopy [15]. The concentration of the test compounds was $20 \mathrm{mg} / \mathrm{ml}$. The concentration for standard, tetracycline (TC), was $10 \mathrm{mg} / \mathrm{ml}$ for screening test. Test compounds were dissolved in dimethylsulphoxide (DMSO). The name of the compounds and their structure are given in Table 1.

\subsection{Antibacterial Activity Screening Test (Disc Diffusion Method) [16]-[18]}

2-3 bacteria colonies were taken in appropriate liquid media and shook it in an incubator shaker for $5 \mathrm{~h}$ at $28^{\circ} \mathrm{C}$ for plant pathogenic bacteria and at $37^{\circ} \mathrm{C}$ for human pathogenic bacteria. The spinning speed maintained at 180 $\mathrm{ppm}$. The bacteria solution was then diluted four times and spread $0.15 \mathrm{ml}$ of this fresh pure culture on media plate with a help of spreader under aseptic condition. Sterile $6 \mathrm{~mm}$ whatman filter paper was used which was impregnated with $10 \mu \mathrm{l}$ of sterile stock solution $(20 \mathrm{mg} / \mathrm{ml})$ of the compound. The filter paper with solution was 
Table 1. Names of the compounds that are used in antibacterial study.

Compound Name

5-Nitro-[1,10]phenanthroline-2,9-dicarbaldehyde

(2,2')-2'-(5-Nitro-1,10-Phenanthroline-2,9-diyl)

bis(methan-1-yl-1-ylidene)bis-(hydrazinecarbodithioate)

(2E,2'E)-Dimethyl-2,2'-(5-nitro-1,10-phenanthroline

-2,9-diyl)bis(methan-1-yl-1-ylidene)bis (hydrazinecarbodithioate)

(2,2')-Benzyl-2,2'-(5-Nitro-1,10-Phenanthroline-2,9-diyl)bis (methan-1-yl-1-ylidene)-bis (hydrazinecarbodithioate)

2,9-Di-(benzo[d]thiazol-2-yl)-5-Nitro-1,10-Phenanthroline

5-Bromo-1,10-phenanthroline-2,9-dicarbaldehyde

(2,2')-2'-(5-Nitro-1,10-Phenanthroline-2,9-diyl) bis(methan-1-yl-1-ylidene)bis-(hydrazinecarbodithioate)

(2E,2'E)-dimethyl-2,2'-(5-bromo-1,10-phenanthroline-2,9-diyl)bis (methan-1-yl-1-ylidene) bis(hydrazinecarbodithioate)

(2,2')-Benzyl

2,2'-(5-bromo-1,10-Phenanthroline-2,9-diyl)bis(methan-1-yl-1-ylidene)-bis (hydrazinecarbodithioate)
Compound Name

Structure

A

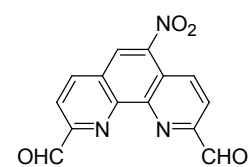

B

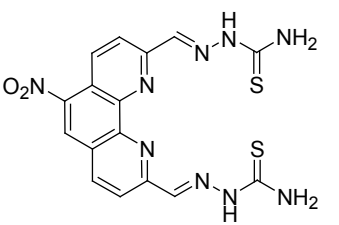

C

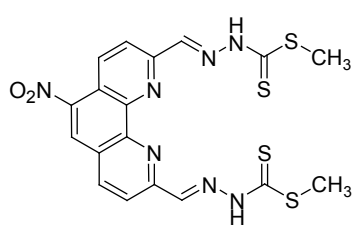

D

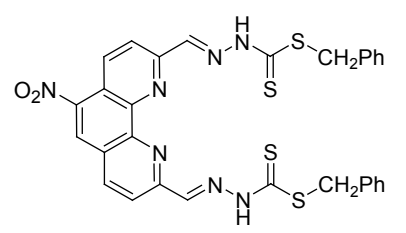

E<smiles>O=[N+]([O-])c1cc2ccc(-c3nc4ccccc4s3)nc2c2nc(-c3nc4ccccc4s3)ccc12</smiles>

F

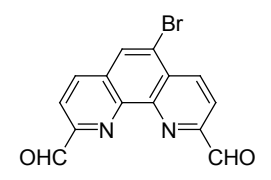

G

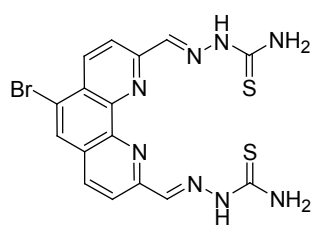

$\mathrm{H}$

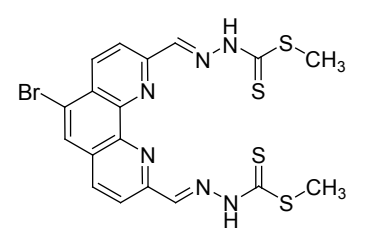

I 


\section{Continued}

2,9-Di-(benzo[d]thiazol-2-yl)-5-bromo-1,10-phenanthroline

2,9-dimethyl-1,10-phenanthroline

5-Bromo-2,9-dimethyl-1,10-phenanthroline

5-Nitro-2,9-dimethyl-1,10-phenanthroline

2,9-Bis-[(tert-butyl-dimethyl-silanyl)-methyl]-[1,10]phenanthroline

5-Bromo-2,9-bis-[(tert-butyl-dimethyl-silanyl)-methyl]-[1,10]phenanthroline<smiles>Brc1cc2ccc(-c3nc4ccccc4s3)nc2nc1-c1nc2ccccc2s1</smiles>

$\mathrm{K}$

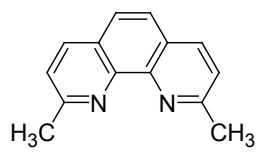

$\mathrm{L}$<smiles>Cc1ccc2cc(Br)c3ccc(C)nc3c2n1</smiles>

M<smiles>Cc1ccc2cc([N+](=O)[O-])c3ccc(C)nc3c2n1</smiles>

$\mathrm{N}$

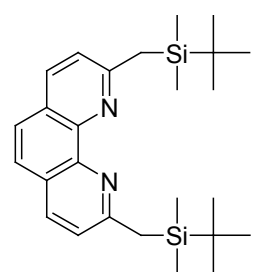

$\mathrm{O}$

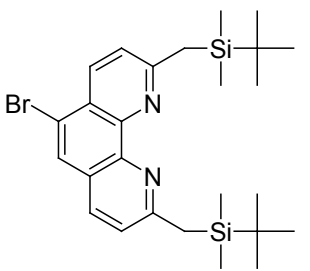

placed in the middle of the bacteria spread media plate. The plates were incubated at appropriate temperature for $24 \mathrm{~h}$. The diameter of the inhibition zone observed was measured in mm scale. Disc impregnated with sterile DMSO was used as a control and with sterile tetracycline (TC) was used as antibacterial reference standard. All tests were performed under sterile conditions in duplicate and repeated three times.

\subsection{Determination of Minimum Inhibitory Concentration (MIC)}

Minimum Inhibitory Concentration (MIC) indicates the lowest concentration of an antimicrobial agent that inhibits the visible growth of a microorganism after overnight incubation. To determine MIC, different variable concentrations of the compounds were used. Media plate and bacteria culture were prepared the same way that were done before in the disk diffusion method. After spreading about $0.15 \mathrm{ml}$ diluted bacteria on the media plate, seven holes were punched on the plate for seven different solutions. $25 \mu \mathrm{L}$ of each solution $\left(\mathrm{T}_{\mathrm{c}}, \mathrm{T}_{0}, \mathrm{~T}_{1}, \mathrm{~T}_{2}, \mathrm{~T}_{3}, \mathrm{~T}_{4}\right.$, $\mathrm{T}_{5}$ ) was put in each hole according to the concentration and kept it in incubator at appropriate temperature for 1 day. The diameter of the inhibition zone was measured in $\mathrm{mm}$ scale and recorded the data. All the tests were repeated three times. 


\section{Results and Discussion}

\subsection{Antibacterial Activity Screening Test}

The antibacterial study is based upon a comparison of inhibition of growth of bacteria by test compounds with that produced by standard antibiotic, Tetracycline (TC). Inhibition zone is the clear region around the paper disc saturated with an antimicrobial agent. The screening result showed that all the compounds exhibited noticeable antibacterial activity against different bacteria. The following Tables show the name of the compounds and antibacterial activity according to the inhibition zones in $\mathrm{mm}$ scale.

The antibacterial activity of compounds against 7 human pathogenic bacteria is presented in Table 2 . The bar charts represent a comparison of the activities of 5-substituted Schiff bases with similar Schiff bases without the substituents. All compounds found to possess antibacterial activity against all human pathogenic bacteria. In fact, compounds showed higher activity for human pathogenic bacteria than plant pathogenic bacteria. Also, it is observed very high activity for silyl derivative, N (Figure 1 and Figure 4). The silyl derivative showed higher activity than tetracycline (TC) in case of Staphylococcus aures, Streptococcus pyogenes, Bacillus subtilus and Listeria monocytogenes. Figure 2 and Figure 3 show graphical representations of antibacterial activity against human pathogenic bacteria. These bacterias are E. Coli MC4100, E. Coli DH5a, Staphylococcus aures, Streptococcus pyogenes, Yersinia enterocoitica 27729, Listeria monocytogenes and Bacillus subtilus.

The antibacterial activity of compounds against 18 plant pathogenic bacteria is presented in Table 3 and Figures 4-6. While all compounds exhibited significant activity, the silyl derivative, $\mathrm{N}$ has higher activity in case of Pectobacterium atosepticum SCR1043, Serratia odorifera 33077, Xanthomonous campestris pv. Pelargonii Xcp42, Xanthomonous campestris pv. Pelargonii Xcp58 and Pantoea sterwartii DC28.

Nine different bacteria of Pseudomonas genre were tested. The result is presented in Table 4. In this case, nitro and bromo aldehyde (A and F) showed higher activity against Pseudomonus Cichorii 302959, Pseudomonas syringae 728 $\alpha$ and Ps.Pv. Morspruorum 218-01 (Figures 7-9).

Table 2. Antibacterial activity of the compounds against human pathogenic bacteria.

\begin{tabular}{|c|c|c|c|c|c|c|c|}
\hline \multirow{2}{*}{ Compound } & \multicolumn{7}{|c|}{ Zone of Inhibition (mm) } \\
\hline & $\begin{array}{l}\text { E. Coli } \\
\text { MC4100 }\end{array}$ & $\begin{array}{l}\text { E. Coli } \\
\text { DH5 } 5\end{array}$ & $\begin{array}{c}\text { Staphylococcus } \\
\text { aureus }\end{array}$ & $\begin{array}{l}\text { Streptococcus } \\
\text { pyogenes }\end{array}$ & $\begin{array}{c}\text { Yersinia } \\
\text { enterocolitica } 27729\end{array}$ & $\begin{array}{c}\text { Listeria } \\
\text { monocytogenes }\end{array}$ & $\begin{array}{l}\text { Bacillus } \\
\text { subtilus }\end{array}$ \\
\hline Medium & LB & LB & TSB & TSB & LB & LB & TSB \\
\hline Std. (TC) & 24 & 24 & 29 & 30 & 40 & 33 & 37 \\
\hline $\mathrm{A}$ & 15 & 14 & 15 & 16 & 15 & 18 & 27 \\
\hline B & 7 & 9 & 8 & 8 & 11 & 9 & 11 \\
\hline $\mathrm{C}$ & 9 & 10 & 01 & 9 & 11 & 9 & 12 \\
\hline $\mathrm{D}$ & 8 & 10 & 8 & 10 & 11 & 12 & 11 \\
\hline $\mathrm{E}$ & 7 & 9 & 7 & 8 & 11 & 9 & 11 \\
\hline $\mathrm{F}$ & 10 & 10 & 14 & 15 & 12 & 16 & 29 \\
\hline G & 7 & 9 & 7 & 10 & 10 & -- & 8 \\
\hline $\mathrm{H}$ & 8 & 9 & 8 & 11 & 10 & 8 & 8 \\
\hline I & 7 & 10 & 8 & 11 & 11 & 11 & 11 \\
\hline $\mathrm{J}$ & 8 & 9 & 9 & 11 & 10 & 16 & 10 \\
\hline $\mathrm{K}$ & 10 & 9 & 15 & 15 & 13 & 30 & 29 \\
\hline $\mathrm{L}$ & 10 & 10 & 9 & 10 & 9 & 22 & 14 \\
\hline $\mathrm{M}$ & 10 & 10 & 12 & 12 & 11 & 14 & 11 \\
\hline $\mathrm{N}$ & 9 & 10 & 21 & 32 & 10 & 29 & 58 \\
\hline $\mathrm{O}$ & 8 & 8 & 10 & 12 & 10 & 21 & 14 \\
\hline
\end{tabular}


Table 3. Antibacterial activity of nine plant pathogenic bacteria.

\begin{tabular}{|c|c|c|c|c|c|c|c|c|c|}
\hline \multirow[b]{2}{*}{ Compound } & \multicolumn{9}{|c|}{ Zone of Inhibition (mm) } \\
\hline & $\begin{array}{l}\text { Pectobacterium } \\
\text { carotovorum } \\
\text { Eec7 }\end{array}$ & $\begin{array}{c}\text { Dickeya } \\
\text { dadantii } \\
3937\end{array}$ & $\begin{array}{l}\text { Pectobacterium } \\
\text { atosepticum } \\
\text { SCR } 1043\end{array}$ & $\begin{array}{c}\text { Serratia } \\
\text { odorifera } \\
33077\end{array}$ & $\begin{array}{c}\text { Pantoea } \\
\text { sterwartii } \\
\text { DC283 }\end{array}$ & $\begin{array}{c}\text { Xanthomonous } \\
\text { campestris pv. } \\
\text { Pelargonii } \\
\text { Xcp42 }\end{array}$ & $\begin{array}{c}\text { Xanthomonous } \\
\text { campestris pv. } \\
\text { Pelargonii } \\
\text { Xcp58 }\end{array}$ & $\begin{array}{l}\text { Pseudomonas } \\
\text { corrugata } \\
301678\end{array}$ & $\begin{array}{c}\text { Pseudomonas } \\
\text { syringae } \\
\text { tomatto } \\
\text { DC3000 }\end{array}$ \\
\hline Medium & LB & LB & LB & LB & LB & NY & $\mathrm{NY}$ & NY & $\mathrm{KB}$ \\
\hline Std. (TC) & 29 & 33 & 28 & 23 & 39 & 41 & 40 & 21 & 31 \\
\hline A & 15 & 10 & 16 & 15 & 19 & 19 & 17 & 14 & 11 \\
\hline B & 11 & 10 & 10 & 8 & 10 & 10 & 10 & 7 & 10 \\
\hline $\mathrm{C}$ & 11 & 11 & 11 & 10 & 12 & 10 & 11 & 9 & 10 \\
\hline $\mathrm{D}$ & 11 & 14 & 12 & 8 & 10 & 10 & 10 & 10 & 12 \\
\hline $\mathrm{E}$ & 10 & 11 & 12 & 8 & 10 & 9 & 10 & 8 & 14 \\
\hline $\mathrm{F}$ & 12 & 11 & 11 & 9 & 14 & 16 & 16 & 10 & 12 \\
\hline $\mathrm{G}$ & 10 & 11 & 10 & 10 & 10 & 10 & 11 & 7 & 10 \\
\hline $\mathrm{H}$ & 11 & 10 & 11 & 8 & 11 & 9 & 10 & 9 & 9 \\
\hline I & 12 & 10 & 11 & 7 & 10 & 11 & 15 & 11 & 11 \\
\hline $\mathrm{J}$ & 10 & 10 & 10 & 10 & 12 & 11 & 10 & 9 & 10 \\
\hline $\mathrm{K}$ & 10 & 10 & 10 & 8 & 15 & 12 & 10 & 10 & 9 \\
\hline $\mathrm{L}$ & 11 & 9 & 10 & 9 & 13 & 11 & 11 & 10 & 10 \\
\hline $\mathrm{M}$ & 10 & 10 & 10 & 7 & 11 & 8 & 14 & 9 & 8 \\
\hline $\mathrm{N}$ & 12 & 13 & 15 & 11 & 65 & 35 & 38 & 11 & 12 \\
\hline $\mathrm{O}$ & 11 & 10 & 9 & 12 & 14 & 12 & 12 & 9 & 10 \\
\hline
\end{tabular}

Table 4. Antibacterial screening test of nine bacteria of Pseudomonas genre.

\begin{tabular}{|c|c|c|c|c|c|c|c|c|c|}
\hline \multirow[b]{2}{*}{ Compound } & \multicolumn{9}{|c|}{ Zone of Inhibition (mm) } \\
\hline & $\begin{array}{l}P . \text { syringae } \\
\text { morspruorum } \\
302756\end{array}$ & $\begin{array}{l}\text { P. cichorii } \\
302959\end{array}$ & $\begin{array}{c}\text { P. aeruginosa } \\
\text { PAO1 }\end{array}$ & P. Savastanoi & P. viridiflava & $\begin{array}{c}P . \text { cichorii } \\
302699\end{array}$ & $\begin{array}{c}\text { P. syringae } \\
\text { FF5 }\end{array}$ & $\begin{array}{c}P . \text { syringae } \\
728 \alpha\end{array}$ & $\begin{array}{c}\text { Ps.Pv. } \\
\text { Morspruorum } \\
218-01\end{array}$ \\
\hline Medium & $\mathrm{KB}$ & $\mathrm{KB}$ & $\mathrm{KB}$ & $\mathrm{KB}$ & $\mathrm{KB}$ & $\mathrm{KB}$ & $\mathrm{KB}$ & $\mathrm{KB}$ & $\mathrm{KB}$ \\
\hline Std. (TC) & 32 & 27 & 10 & 40 & 25 & 29 & 27 & 26 & 25 \\
\hline A & 13 & 50 & 12 & 15 & 13 & 12 & 11 & 13 & 15 \\
\hline B & 7 & 7 & 7 & 10 & 7 & 7 & 7 & 8 & 7 \\
\hline $\mathrm{C}$ & 7 & 7 & 7 & 10 & 9 & 8 & 10 & 8 & 8 \\
\hline $\mathrm{D}$ & 7 & 7 & 7 & 10 & 7 & 9 & 11 & 7 & 8 \\
\hline $\mathrm{E}$ & 7 & -- & 7 & 10 & -- & 7 & 7 & -- & 11 \\
\hline $\mathrm{F}$ & 13 & 37 & 10 & 12 & 11 & 10 & 12 & 24 & 19 \\
\hline $\mathrm{G}$ & 7 & 7 & 7 & 9 & 8 & 8 & 8 & 7 & 8 \\
\hline $\mathrm{H}$ & 7 & 7 & 8 & 19 & -- & 7 & 7 & 9 & 7 \\
\hline I & 7 & 7 & 7 & 10 & 7 & 8 & 8 & 8 & 11 \\
\hline $\mathrm{J}$ & 8 & 7 & 8 & 10 & 7 & 7 & 8 & 7 & 10 \\
\hline $\mathrm{K}$ & -- & -- & 7 & 9 & 7 & 8 & 7 & 7 & -- \\
\hline $\mathrm{L}$ & 9 & 8 & 7 & 9 & 8 & 8 & 7 & 8 & 8 \\
\hline $\mathrm{M}$ & 8 & 8 & 7 & 9 & 8 & 8 & 8 & 8 & 8 \\
\hline $\mathrm{N}$ & 9 & 9 & -- & 9 & 9 & 7 & 11 & 11 & 12 \\
\hline $\mathrm{O}$ & 7 & 8 & 7 & 9 & 7 & 8 & 9 & 7 & 9 \\
\hline
\end{tabular}



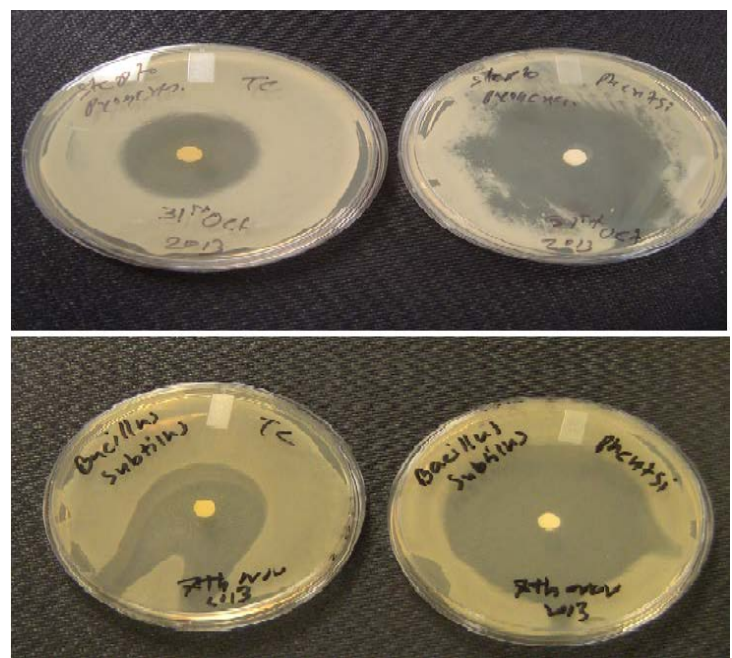

Figure 1. Photos of the antibacterial test of compound $\mathrm{N}$ and standard.

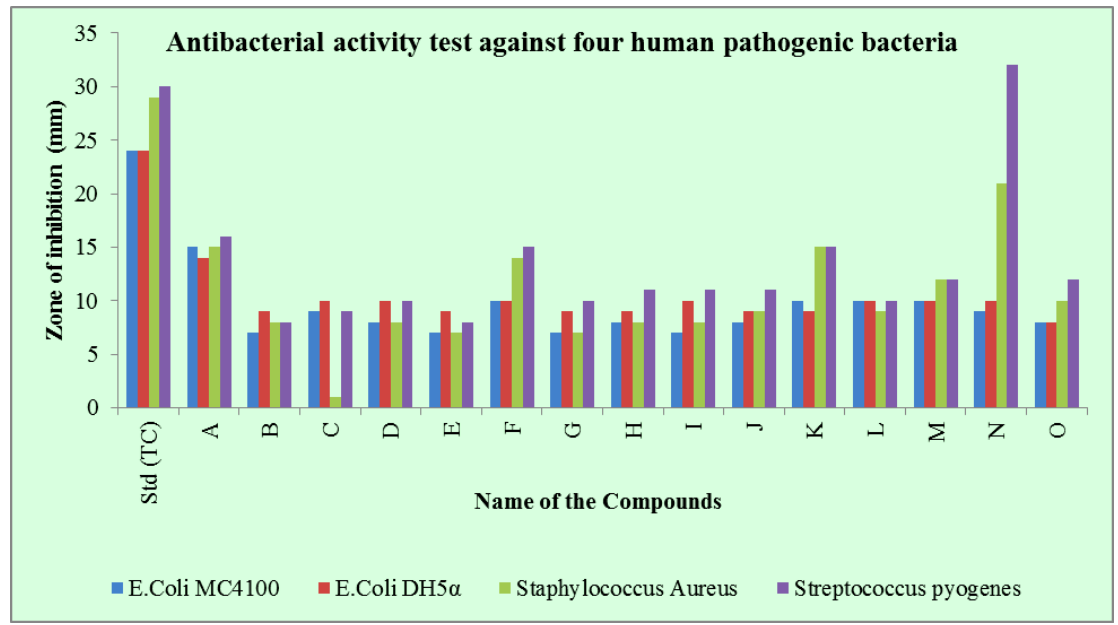

Figure 2. Antibacterial activity test against four human pathogenic bacteria.

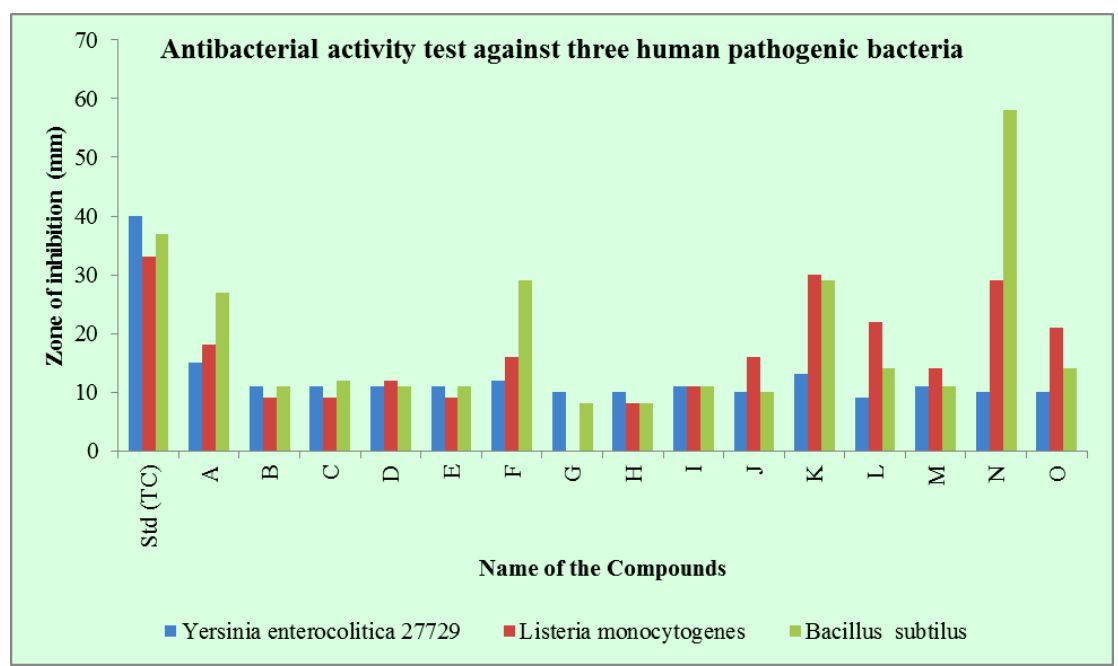

Figure 3. Antibacterial activity test against three human pathogenic bacteria. 

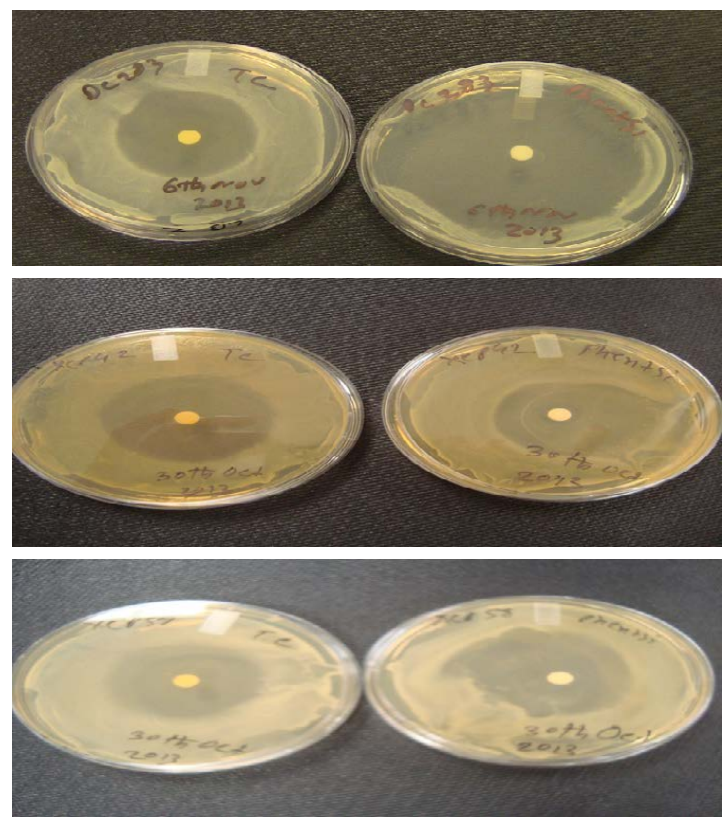

Figure 4. Some real pictures of the high activity of silyl methyl phenanthroline compound, N against Pantoea sterwartii DC283, Xanthomonous campestris pv. Pelargonii Xcp42, Xanthomonous campestris pv. Pelargonii Xcp58.

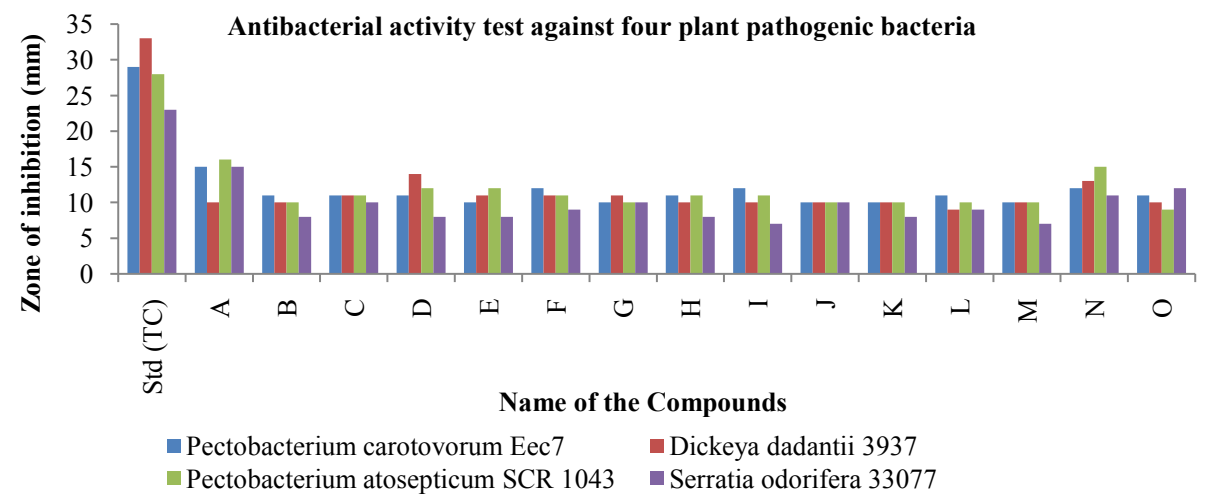

Figure 5. Antibacterial activity test against four plant pathogenic bacteria.

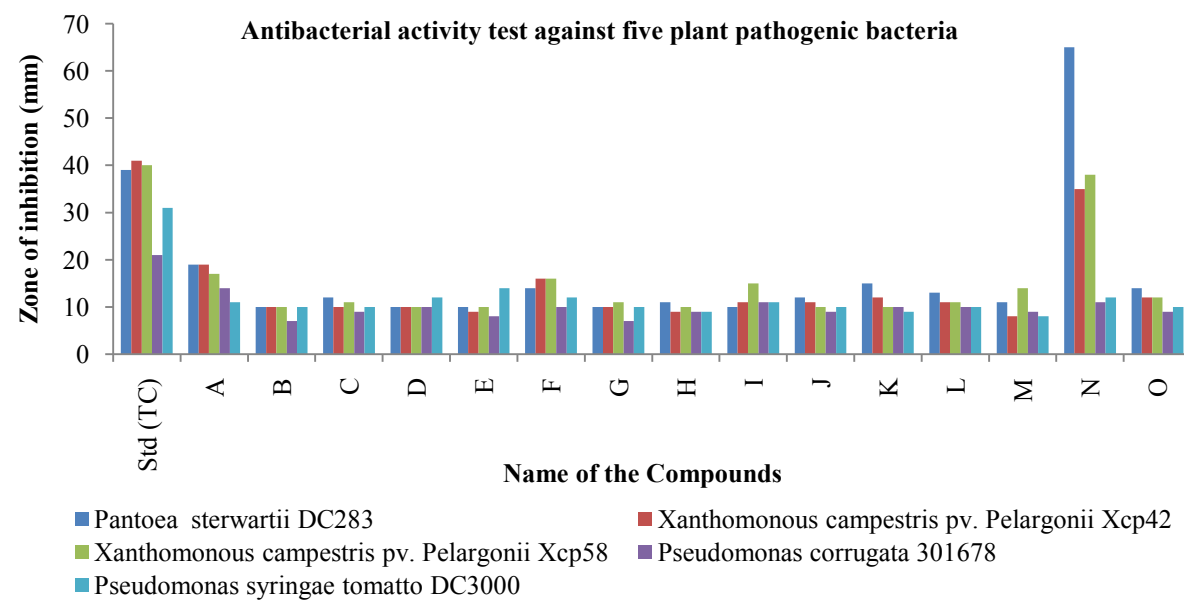

Figure 6. Antibacterial activity test against five plant pathogenic bacteria. 

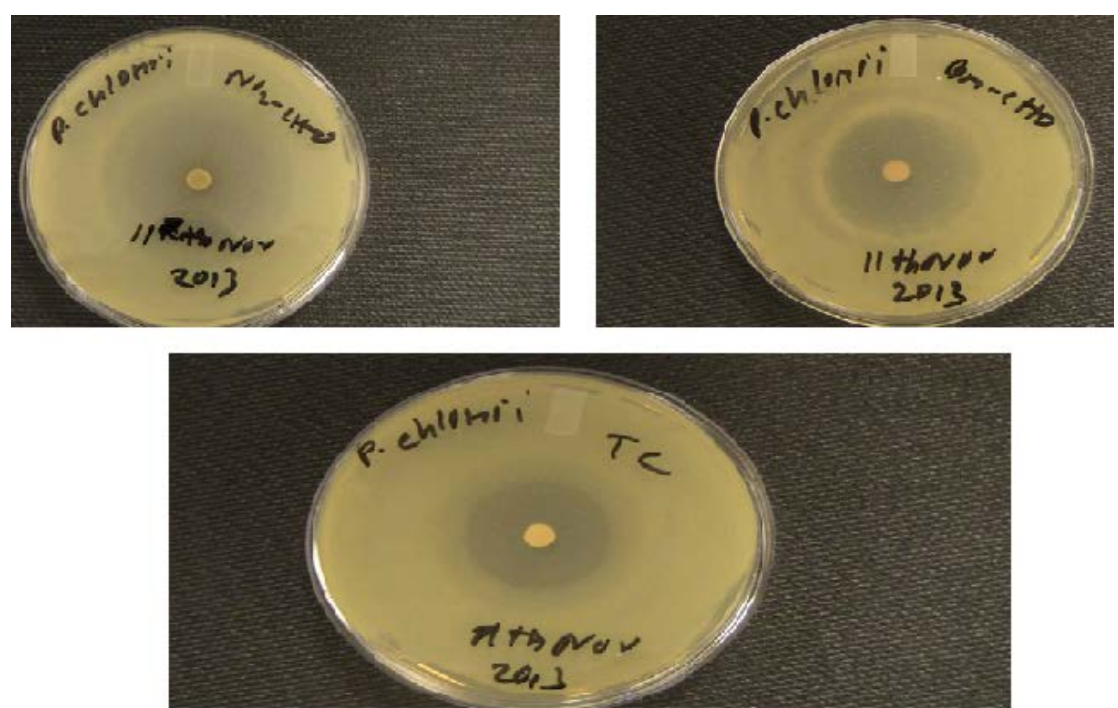

Figure 7. Photo of antibacterial test of bromo, F and nitro aldehyde, A against Pseudomonas cichorii.

Antibacterial activity test against four plant pathogenic bacteria

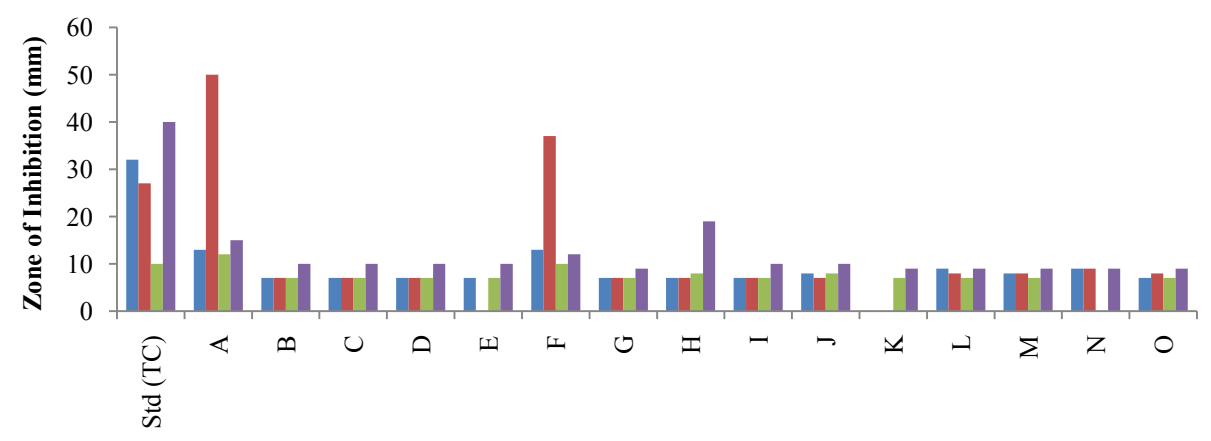

Name of the Compounds

—P. syringae morspruorum302756 $\backsim$ P. cichorii $302959 \backsim$ P. aeruginosa PAO1 $\backsim$ P. Savastanoi

Figure 8. Antibacterial activity test against four plant pathogenic bacteria.

Antibacterial activity test against five plant pathogenic bacteria

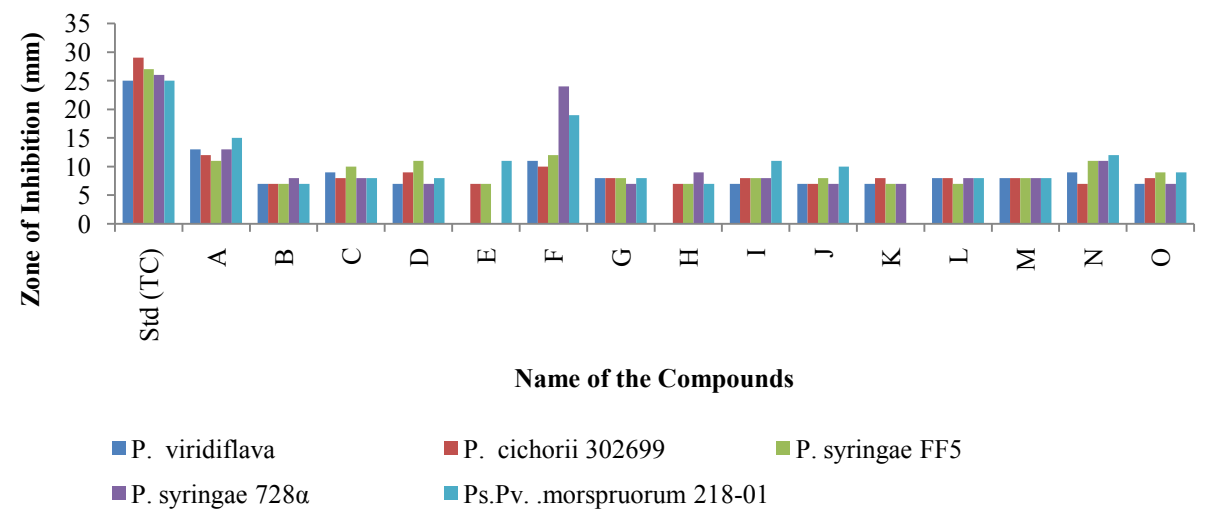

Figure 9. Antibacterial activity test against five plant pathogenic bacteria. 


\subsection{Minimum Inhibitory Concentration (MIC)}

Minimum inhibitory concentration (MIC) is the minimum concentration of the test compound that inhibits the visual growth of the microorganism. MIC was determined for those compounds that showed higher activity on some bacteria. 5 Different concentrated solutions of the compounds were used to test MIC starting from 100 $\mu \mathrm{g} / \mathrm{ml}$ to $5 \mathrm{mg} / \mathrm{ml}$. In all cases, the MIC of silyl methyl phenanthroline, N (Figure 10 and Figure 11) was found to be $100 \mu \mathrm{g} / \mathrm{ml}$ toward Streptococcus pyogenes, Listeria monocytogenes, Bacillus subtilus, Xanthomonous campestris pv. Pelargonii Xcp42, Xanthomonous campestris pv. Pelargonii Xcp58, Pantoea sterwartii DC283 (Table 5). Also, for nitro aldehyde, A, $100 \mu \mathrm{g} / \mathrm{ml}$ was the MIC for Streptococcus pyogenes, Listeria monocytogenes, Xanthomonous campestris pv. Pelargonii Xcp42, Xanthomonous campestris pv. Pelargonii Xcp58, E. coli MC4100, Pseudomonas syringae Morspruorum 302756 and $200 \mu \mathrm{g} / \mathrm{ml}$ was the MIC for Bacillus subtilus (Figure 12 and Figure 13). All the results are shown in Table 6 and Table 7. Moreover, $100 \mu \mathrm{g} / \mathrm{ml}$ was the MIC for bromo aldehyde, F against Streptococcus pyogenes, Bacillus subtilus, Listeria monocytogenes, Xanthomonous campestris pv. Pelargonii Xcp42, Xanthomonous campestris pv. Pelargonii Xcp58, Pseudomonus Cichorii 302959 (Figure 14 and Figure 15). Table 8 and Figure 16 show summary of results.
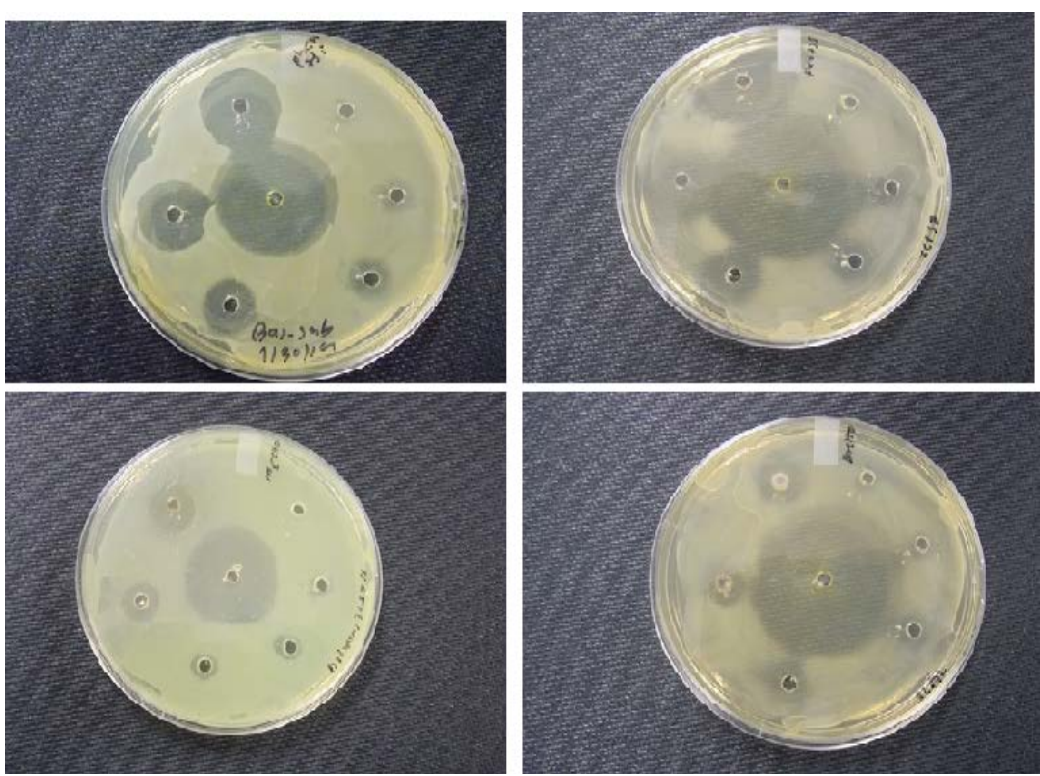

Figure 10. Pictures of minimum inhibitory concentration (MIC) test for the Compound $\mathrm{N}$.

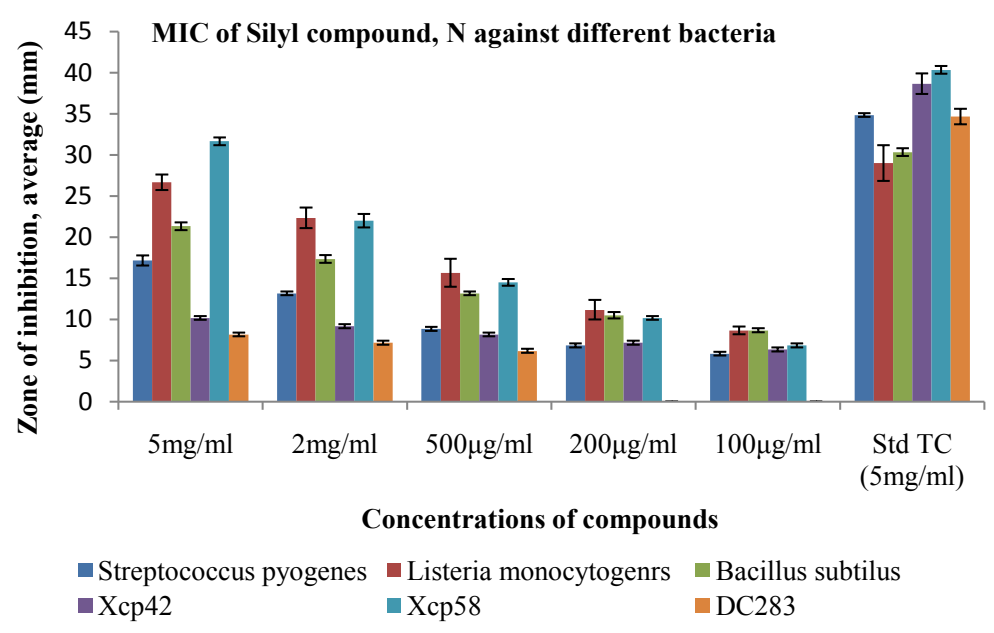

Figure 11. MIC of Silyl compound, N against different bacteria. 


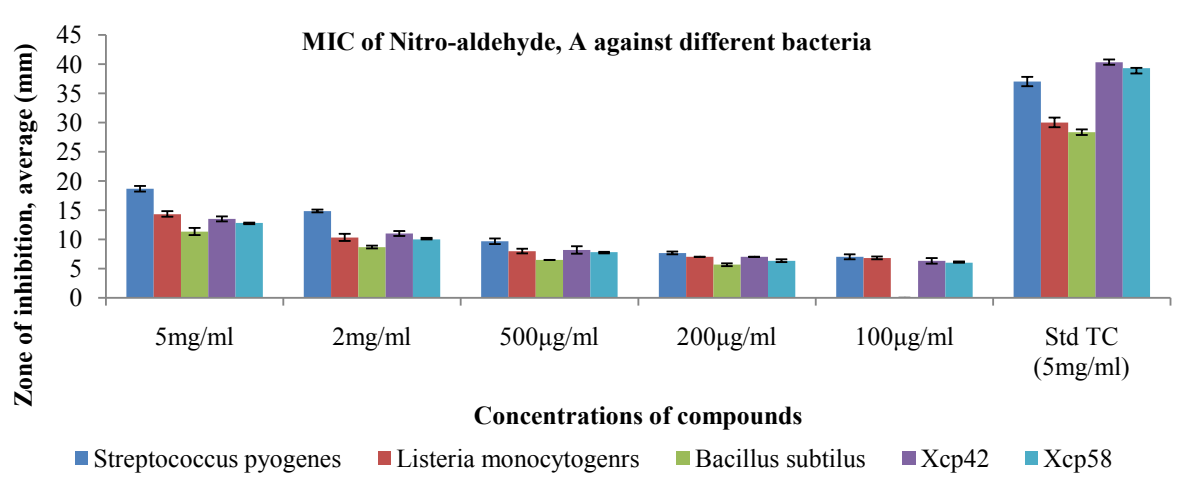

Figure 12. MIC of Nitro-aldehyde, A against five bacteria.

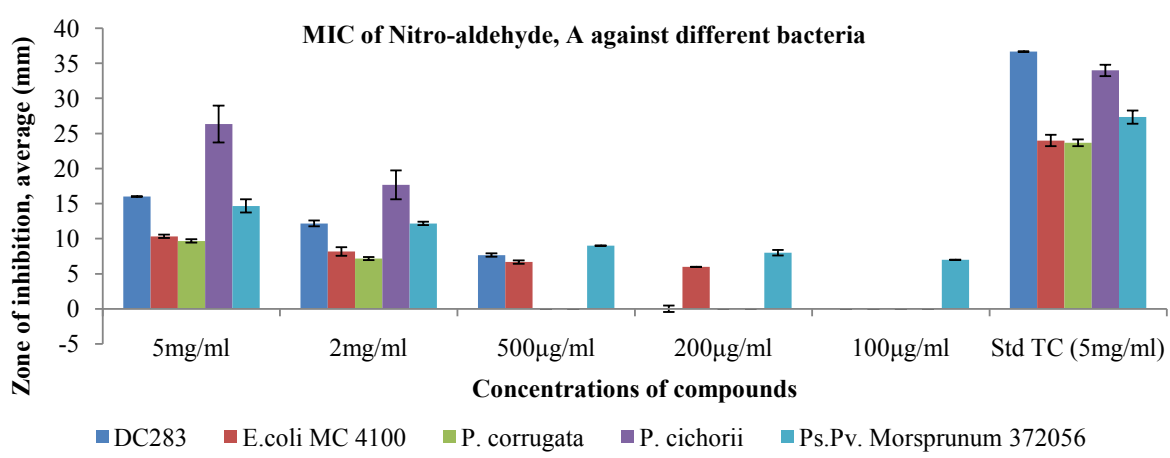

Figure 13. MIC of Nitro-aldehyde, A against six bacteria.

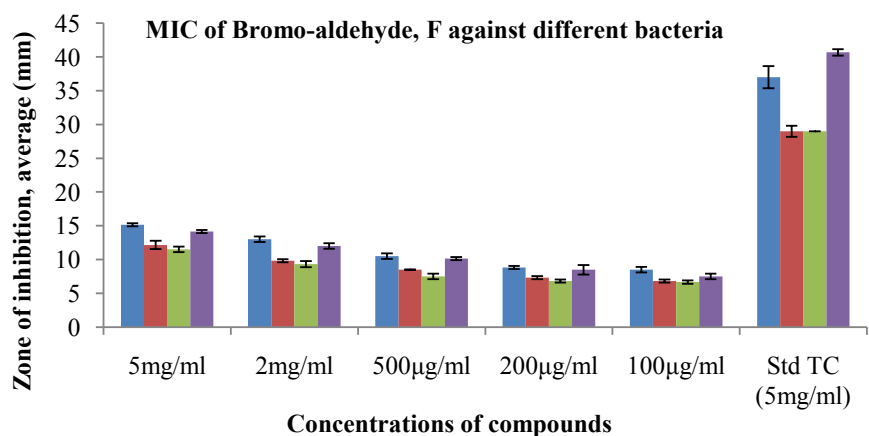

$\backsim$ Streptococcus pyogenes $\backsim$ Listeria monocytogenrs $\approx$ Bacillus subtilus $\backsim$ Xcp42

Figure 14. MIC of Bromo-aldehyde, F against four bacteria.

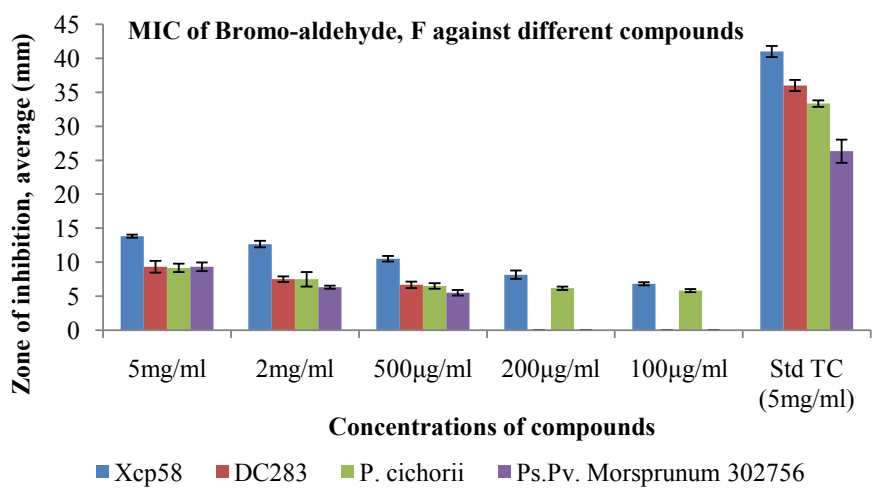

Figure 15. MIC of Bromo-aldehyde, F against four bacteria. 


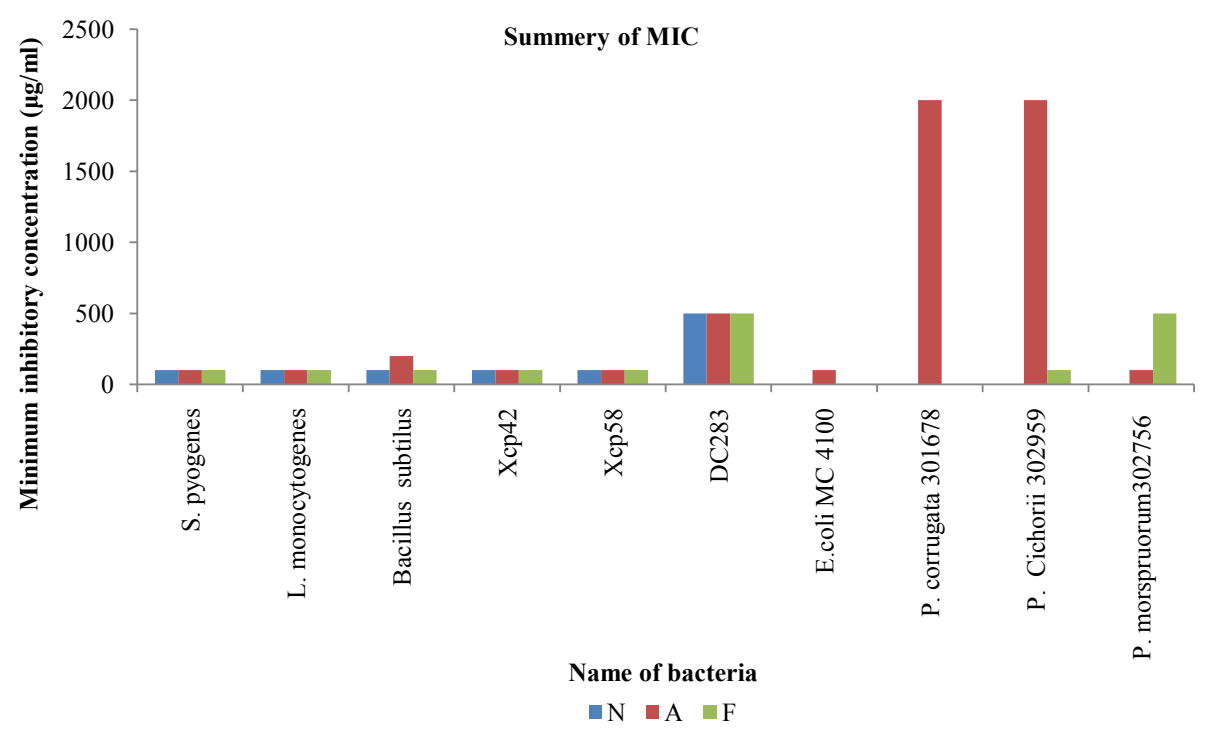

Figure 16. Overall summery of MIC test.

Table 5. Minimum inhibitory concentration (MIC) of Silyl methyl Phenanthroline compound, N.

\begin{tabular}{|c|c|c|c|c|c|c|}
\hline \multirow[b]{2}{*}{ Name of Bacteria } & \multicolumn{6}{|c|}{ Zone of Inhibition (mm) of Silyl Methyl Phenanthroline, N } \\
\hline & $5 \mathrm{mg} / \mathrm{ml}$ & $2 \mathrm{mg} / \mathrm{ml}$ & $500 \mu \mathrm{g} / \mathrm{ml}$ & $200 \mu \mathrm{g} / \mathrm{ml}$ & $100 \mu \mathrm{g} / \mathrm{ml}$ & $\begin{array}{l}\text { Std. TC } \\
(5 \mathrm{mg} / \mathrm{ml})\end{array}$ \\
\hline Streptococcus pyogenes & $17.17 \pm 0.62$ & $13.17 \pm 0.24$ & $8.83 \pm 0.24$ & $6.83 \pm 0.23$ & $5.83 \pm 0.24$ & $34.83 \pm 0.23$ \\
\hline Listeria monocytogenes & $26.67 \pm 0.94$ & $22.33 \pm 1.25$ & $15.67 \pm 1.7$ & $11.17 \pm 1.18$ & $8.67 \pm 0.47$ & $29 \pm 2.16$ \\
\hline Bacillus subtilus & $21.33 \pm 0.47$ & $17.33 \pm 0.47$ & $13.17 \pm 0.24$ & $10.5 \pm 0.41$ & $8.67 \pm 0.24$ & $30.33 \pm 0.47$ \\
\hline $\begin{array}{c}\text { Xanthomonous campestris pv. } \\
\text { pelargonii Xcp42 }\end{array}$ & $10.17 \pm 0.24$ & $9.17 \pm 0.24$ & $8.17 \pm 0.24$ & $7.17 \pm 0.24$ & $6.33 \pm 0.24$ & $38.67 \pm 1.25$ \\
\hline $\begin{array}{c}\text { Xanthomonous campestris pv. } \\
\text { pelargonii Xcp58 }\end{array}$ & $31.67 \pm 0.47$ & $22 \pm 0.82$ & $14.5 \pm 0.41$ & $10.17 \pm 0.24$ & $6.83 \pm 0.24$ & $40.33 \pm 0.47$ \\
\hline Pantoea sterwartii DC283 & $8.17 \pm 0.24$ & $7.17 \pm 0.24$ & $6.17 \pm 0.24$ & $0 \pm 0$ & $0 \pm 0$ & $34.67 \pm 0.94$ \\
\hline
\end{tabular}

Table 6. Minimum inhibitory concentration (MIC) of nitro aldehyde, A compound.

\begin{tabular}{|c|c|c|c|c|c|c|}
\hline \multirow[b]{2}{*}{ Name of Bacteria } & \multicolumn{6}{|c|}{ Zone of Inhibition (mm) of Nitro Aldehyde, A } \\
\hline & $5 \mathrm{mg} / \mathrm{ml}$ & $2 \mathrm{mg} / \mathrm{ml}$ & $500 \mu \mathrm{g} / \mathrm{ml}$ & $200 \mu \mathrm{g} / \mathrm{ml}$ & $100 \mu \mathrm{g} / \mathrm{ml}$ & $\begin{array}{l}\text { Std. TC } \\
(5 \mathrm{mg} / \mathrm{ml})\end{array}$ \\
\hline Streptococcus pyogenes & $18.67 \pm 0.47$ & $14.83 \pm 0.24$ & $9.67 \pm 0.47$ & $7.67 \pm 0.24$ & $7 \pm 0.41$ & $37 \pm 0.82$ \\
\hline Listeria monocytogenes & $14.33 \pm 0.47$ & $10.33 \pm 0.62$ & $8 \pm 0.41$ & $7 \pm 0$ & $6.83 \pm 0.24$ & $30 \pm 0.82$ \\
\hline Bacillus subtilus & $11.33 \pm 0.62$ & $8.67 \pm 0.24$ & $6.5 \pm 0$ & $5.67 \pm 0.24$ & $0 \pm 0$ & $28.33 \pm 0.47$ \\
\hline $\begin{array}{c}\text { Xanthomonous campestris pv. } \\
\text { Pelargonii Xcp42 }\end{array}$ & $13.5 \pm 0.41$ & $11 \pm 0.41$ & $8.17 \pm 0.62$ & $7 \pm 0$ & $6.33 \pm 0.47$ & $40.33 \pm 0.47$ \\
\hline $\begin{array}{c}\text { Xanthomonous campestris pv. } \\
\text { Pelargonii Xcp58 }\end{array}$ & $12.83 \pm 0.24$ & $10 \pm 0$ & $7.83 \pm 0.24$ & $6.33 \pm 0.24$ & $6 \pm 0$ & $39.33 \pm 0.94$ \\
\hline Pantoea sterwartii DC283 & $16 \pm 0.41$ & $12.17 \pm 0.24$ & $7.67 \pm 0.47$ & $0 \pm 0$ & $0 \pm 0$ & $36.67 \pm 1.25$ \\
\hline E. coli MC4100 & $10.33 \pm 0.24$ & $8.17 \pm 0.62$ & $6.67 \pm 0.24$ & $6 \pm 0$ & $0 \pm 0$ & $24 \pm 0.82$ \\
\hline Pseudomonas corrugata 301678 & $9.67 \pm 0.24$ & $7.17 \pm 0.24$ & $0 \pm 0$ & $0 \pm 0$ & $0 \pm 0$ & $23.67 \pm 0.47$ \\
\hline Pseudomonus cichorii 302959 & $26.33 \pm 2.62$ & $17.67 \pm 2.05$ & $0 \pm 0$ & $0 \pm 0$ & $0 \pm 0$ & $34 \pm 0.82$ \\
\hline $\begin{array}{c}\text { Pseudomonas syringae } \\
\text { morspruorum } 302756\end{array}$ & $14.67 \pm 0.94$ & $12.17 \pm 0.24$ & $9 \pm 0$ & $8 \pm 0.41$ & $7 \pm 0$ & $27.33 \pm 0.94$ \\
\hline
\end{tabular}


Table 7. Minimum inhibitory concentration (MIC) of bromo aldehyde, F compound.

\begin{tabular}{ccccccc}
\hline & \multicolumn{5}{c}{ Zone of Inhibition (mm) of Bromo Aldehyde, F } \\
\cline { 2 - 7 } Name of Bacteria & $5 \mathrm{mg} / \mathrm{ml}$ & $2 \mathrm{mg} / \mathrm{ml}$ & $500 \mu \mathrm{g} / \mathrm{ml}$ & $200 \mu \mathrm{g} / \mathrm{ml}$ & $100 \mu \mathrm{g} / \mathrm{ml}$ & $\begin{array}{c}\text { Std. TC } \\
(5 \mathrm{mg} / \mathrm{ml})\end{array}$ \\
\hline $\begin{array}{c}\text { Streptococcus pyogenes } \\
\text { Listeria monocytogenes }\end{array}$ & $15.17 \pm 0.24$ & $13 \pm 0.41$ & $10.5 \pm 0.41$ & $8.83 \pm 0.24$ & $8.5 \pm 0.41$ & $37 \pm 1.63$ \\
$\quad 12.17 \pm 0.62$ & $9.83 \pm 0.24$ & $8.5 \pm 0$ & $7.33 \pm 0.24$ & $6.83 \pm 0.24$ & $29 \pm 0.82$ \\
$\begin{array}{c}\text { Bacillus subtilus } \\
\text { Xanthomonous campestris pv. }\end{array}$ & $11.5 \pm 0.41$ & $9.33 \pm 0.47$ & $7.5 \pm 0.41$ & $6.83 \pm 0.24$ & $6.67 \pm 0.24$ & $29 \pm 0$ \\
$\begin{array}{c}\text { pelargonii Xcp42 } \\
\text { Xanthomonous campestris pv. }\end{array}$ & $14.17 \pm 0.24$ & $12 \pm 0.41$ & $10.17 \pm 0.24$ & $8.5 \pm 0.71$ & $7.5 \pm 0.41$ & $40.67 \pm 0.47$ \\
$\begin{array}{c}\text { pelargonii Xcp58 } \\
\text { Pantoea sterwartii DC283 }\end{array}$ & $13.83 \pm 0.24$ & $12.67 \pm 0.47$ & $10.5 \pm 0.41$ & $8.17 \pm 0.62$ & $6.83 \pm 0.24$ & $41 \pm 0.82$ \\
$\begin{array}{c}\text { Pseudomonus cichorii 302959 } \\
\text { Pseudomonas syringae }\end{array}$ & $9.33 \pm 0.85$ & $7.5 \pm 0.41$ & $6.67 \pm 0.47$ & $0 \pm 0$ & $0 \pm 0$ & $36 \pm 0.82$ \\
morspruorum 302756 & $9.17 \pm 0.62$ & $7.5 \pm 1.08$ & $6.5 \pm 0.41$ & $6.17 \pm 0.24$ & $5.83 \pm 0.24$ & $33.33 \pm 0.47$ \\
\hline
\end{tabular}

Table 8. Overall summary of MIC.

\begin{tabular}{cccc}
\hline Name of the Bacteria & \multicolumn{2}{c}{ Minimum Inhibitory Concentration $(\mu \mathrm{g} / \mathrm{mL})$} \\
\cline { 2 - 4 } Streptococcus pyogenes & $\mathrm{N}$ & $\mathrm{A}$ & $\mathrm{F}$ \\
Listeria monocytogenes & 100 & 100 & 100 \\
Bacillus subtilus & 100 & 100 & 100 \\
Xanthomonous campestris pv. pelargonii Xcp42 & 100 & 200 & 100 \\
Xanthomonous campestris pv. pelargonii Xcp58 & 100 & 100 & 100 \\
Pantoea sterwartii DC283 & 100 & 100 & 500 \\
E. coli MC4100 & 500 & 500 & -- \\
Pseudomonas corrugata 301678 & -- & 100 & -- \\
Pseudomonus cichorii 302959 & -- & 2000 & 100 \\
Pseudomonas syringae morspruorum 302756 & -- & 2000 & 500 \\
\hline
\end{tabular}

\section{Conclusion}

Antibacterial studies of 15 different compounds including intermediate silyl and aldehyde compounds were carried out. These compounds were tested on 18 plants and 7 human pathogenic bacteria. The antibacterial activity screening test of the synthesized compounds was initially examined by paper disc diffusion technique. In screening test, the compounds showed higher antibacterial activity for human pathogenic bacteria. High activity was observed for silyl derivative as well. Compound $\mathrm{N}$ was even more active than the standard tetracycline (TC). Moreover, it has been found that the activity of the 5-substituted Schiff bases has shown higher activity than their non- substituted members. Finally, the minimum inhibitory concentrations (MIC) of the compounds were determined by tube dilution method. For most of the compounds MIC was $100 \mu \mathrm{g} / \mathrm{ml}$.

\section{References}

[1] Bell, S.C., Conklin, G.L. and Childress, S.J. (1963) The Separation of Ketimine Isomers. Journal of the American Chemical Society, 85, 2868-2869. http://dx.doi.org/10.1021/ja00901a057

[2] Khan, S.A., Siddiqui, A.A. and Bhatt, S. (2002) Analgesic Activity of Isatin Derivatives. Asian Journal of Chemistry, 14, 1117-1118.

[3] Capdeville, R., Buchdunger, E., Zinnermann, J. and Matter, A. (2002) Glivec (ST1571, Imatnib, a Rationally Developed, Targeted Anticancer Drug. Nature Reviews Drug Discovery, 1, 493-502. http://dx.doi.org/10.1038/nrd839

[4] Raman, N., Kulandaisamy, A., Shunmugasundaram, A. and Jeyasubramanian, K. (2001) Synthesis, Spectral, Redox 
and Antimicrobial Activities of Schiff Base Complexes Derived from 1-Phenyl-2,3-dimethyl-4-aminopyrazol-5-one and Acetoacetanilide. Transition Metal Chemistry, 26, 131-135. http://dx.doi.org/10.1023/A:1007100815918

[5] Shivarama, H.B., Sooryanarayana, R.B., Shridhara, K. and Akber, A.P.M. (2000) Studies on arylfuran Derivatives: Part XI. Synthesis, Characterization and Biological Studies on Some Mannich Bases Carrying 2,4-Dichlorophenylfurfural Moiety. Il Farmaco, 54, 338-344. http://dx.doi.org/10.1016/S0014-827X(00)00033-1

[6] Chaha, V.K., Ranwa, N.S. and Dadheech, P.K. (1998) Synthesis and Screening of Biological Activity of Triazolothiadiazines and Triazolothiadiazoles. Journal of Phytological Research, 11, 201-202.

[7] Sahu, R., Thakur, D.S. and Kashyap, P. (2012) Schiff Base: An Overview of Its Medicinal Chemistry Potential of New Drug Molecules. International Journal of Pharmaceutical Sciences and Nanotechnology, 5, 1757-1764.

[8] Mancin, F., Scrimin, P., Tecillab, P. and Tonellatoa, U. (2005) Artificial Metallonucleases. Chemical Communications, 2540-2548. http://dx.doi.org/10.1039/b418164f

[9] Cowan, A.J. (2001) Chemical Nucleases. Current Opinion in Chemical Biology, 5, 634-642.

[10] Goswami, K.T., Gadadhar, S., Karande, A.A. and Chakravarty, R.A. (2013) Photocytotoxic Ferrocene-Appended (LTyrosine)Copper(II) Complexes of Phenanthroline Bases. Polyhedron, 52, 1287-1298. http://dx.doi.org/10.1016/j.poly.2012.06.018

[11] Wheate, N.J., Taleb, R.I., Krause-Heuer, A.M., Cook, R.L., Wang, S., Higgins, V.J. and Aldrich-Wright, J.R. (2007) Novel Platinum(II)-Based Anticancer Complexes and Molecular Hosts as Their Drug Delivery Vehicles. Dalton Transactions, 43, 5055-5064.

[12] Klayman, D.L., Bartosevich, J.F., Griffin, T.S., Mason, C.J. and Scovill, J.P. (1979) 2-Acetylpyridine Thiosemicarbazones. 1. A New Class of Potential Antimalarial Agents. Journal of Medicinal Chemistry, 22, 855-862. http://dx.doi.org/10.1021/jm00193a020

[13] Borhade, S.S. (2013) Synthesis, Antibacterial Activity of New Fatty Acid Thiosemicarbazide from Linum Usitatissimum (Linseed) Seed Oil and It's Characterization by X-RD. Der Pharmacia Sinica, 4, 118-124.

[14] Sartorelli, A.C. and Booth, B.A. (1967) Inhibition of the Growth of Sarcoma 180 Ascites Cells by Combinations of Inhibitors of Nucleic Acid Biosynthesis and the Cupric Chelate of Kethoxal Bis-(Thiosemicarbazone). Cancer Research, 27, 1614-1619.

[15] Jaman, Z., Karim, R.M., Siddiquee, A.T., Mirza, H.A. and Ali, A.M. (2013) Synthesis of 5-Substituted 2, 9-dimethyl1,10-phenanthroline Dialdehydes and Their Schiff Bases with Sulfur-Containing Amines. International Journal of Organic Chemistry, 3, 214-219. http://dx.doi.org/10.4236/ijoc.2013.33029

[16] Cowan, M.M. (1999) Plan Product as Antibacterial Agents. Clinical Microbiology Reviews, 12, 564-582.

[17] Cushnie, T.P.T. and Lamb, A.J. (2005) Antimicrobial Activity of Flavoboids. International Journal of Antimicrobial Agents, 26, 343-356. http://dx.doi.org/10.1016/j.ijantimicag.2005.09.002

[18] Kadam, S.S., Mahadik, K.R. and Bothara, K.G. (2001) Principle of Medicinal Chemistry. 18th Edition, Nirali Prokashan, Delhi. 
Scientific Research Publishing (SCIRP) is one of the largest Open Access journal publishers. It is currently publishing more than 200 open access, online, peer-reviewed journals covering a wide range of academic disciplines. SCIRP serves the worldwide academic communities and contributes to the progress and application of science with its publication.

Other selected journals from SCIRP are listed as below. Submit your manuscript to us via either submit@scirp.org or Online Submission Portal.
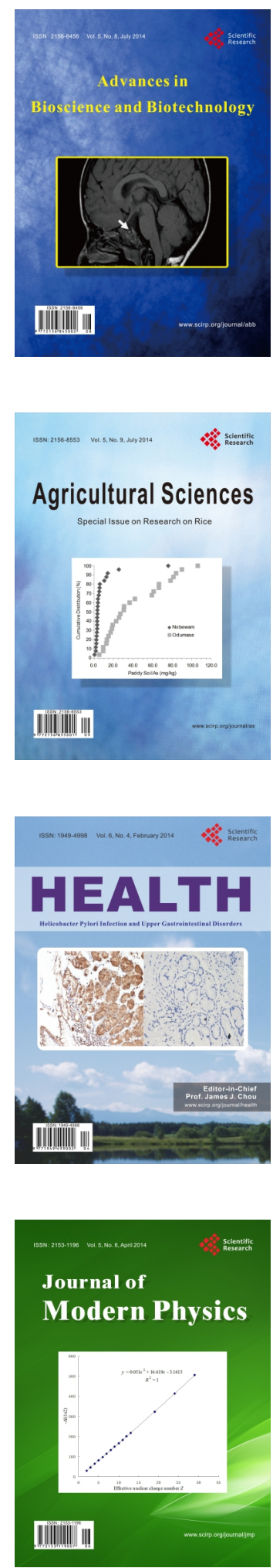
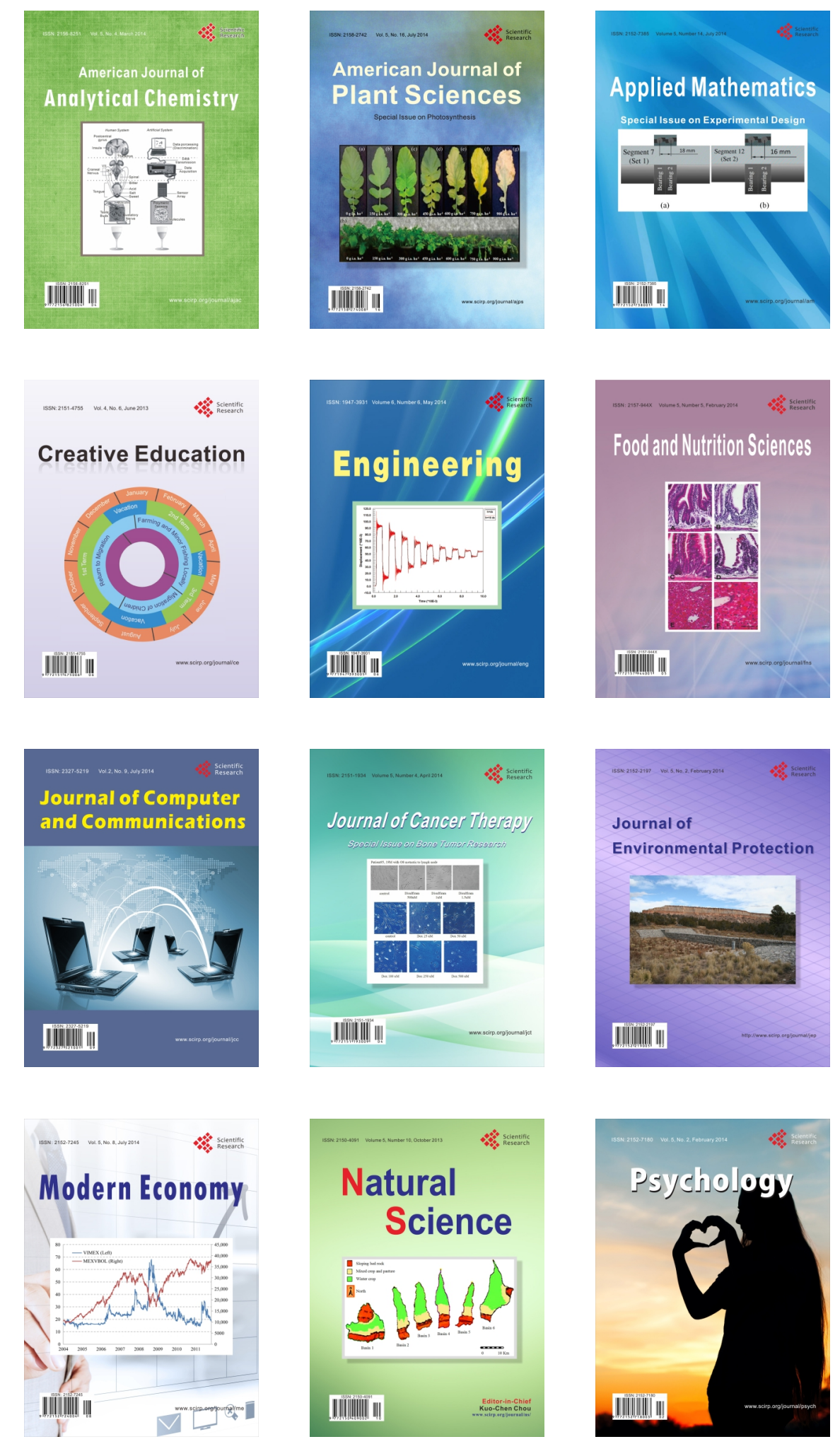